\title{
Examining Learning Styles with Gender Comparison Among Medical Students of a Saudi University
}

This article was published in the following Dove Press journal:

Advances in Medical Education and Practice

\author{
Abdullah Bin Eid (D) \\ Mohammed Almutairi (D) \\ Abdulwahed Alzahrani $\mathbb{D}^{\prime}$ \\ Fahad Alomair (D) \\ Abdulaziz Albinhamad' \\ Yazieed Albarrak' \\ Mohammed Alzuaki (D) \\ Salman Alyahya' \\ Khalid Bin Abdulrahman (D) ${ }^{2}$ \\ 'College of Medicine, Al-Imam \\ Mohammad Ibn Saud Islamic University in \\ Riyadh, Riyadh, Saudi Arabia; \\ ${ }^{2}$ Department of Medical Education \\ College of Medicine, Al-Imam \\ Mohammad Ibn Saud Islamic University in \\ Riyadh, Riyadh, Saudi Arabia
}

\begin{abstract}
Aim: Different students use different learning styles and acquire knowledge from various sources during their medical college learning journey. Every student has a preference for a certain sensory mode to receive and process all acquired information. Identifying learning styles among different students can help students try to strengthen their preferred learning style and improve other nonpreferred learning styles. Our objective is to assess the preferred sensory modality and the learning preferences by utilizing the VARK questionnaire in medical faculty students at Imam Mohammed Bin Saud Islamic University (IMBSU) and the influence of gender and its relation to academic achievements.
\end{abstract}

Methodology: A survey was distributed to medical students of IMBSU in Riyadh. VARK questionnaire was used to assess the learning preference. Other questions regarding demographic data were also included in the same questionnaire.

Results: Of the 146 students, 113 students completed the questionnaire. Of them, 95 $(84.1 \%)$ were males, and $18(15.9 \%)$ were females. The multimodal learning style was preferred by $70 \%$ of the respondents, with the remaining $30 \%$ having a unimodal style preference. The aural (A) and the kinesthetic (K) styles were the most preferred unimodal styles. Overall, the most common style was the quad-modal (VARK type 2) style, with $21.20 \%$ having this preference.

Conclusion: No statistically significant differences were observed between male and female students concerning their learning preferences. The participants' preferred learning style or learning model was also observed to have no statistically significant impact on GPA and academic performance.

Keywords: learning styles, Saudi Arabia, medical students, VARK

\section{Introduction}

Different students use different styles of learning and acquiring knowledge from various sources during their learning journey. Learning styles could be defined as "an individual's natural, habitual and preferred way of absorbing, processing and retaining new information and skills". ${ }^{1}$ Learning styles are diverse among different students, with a preference for a certain sensory mode to receive and process that acquired information. ${ }^{2}$ Thus, identifying learning styles among different students is essential, helping students try to strengthen their preferred learning style and improve other nonpreferred learning styles. ${ }^{3}$

Different models were built to try to explain different learning styles. ${ }^{4}$ One of these models, known as VARK (an acronym) developed by Neil Fleming, is used to assess learning styles. Students can identify their preferred learning style based on the sensory modalities involved in students' learning processes. ${ }^{5}$
Correspondence: Abdullah Bin Eid Alharfain, 6540, Laban Riyadh, Saudi Arabia

Tel +966599707088

Email Eid.abdullah2@gmail.com
Advances in Medical Education and Practice 2021:12 309-318

DovePress in 
VARK is based on three main concepts, which are: everyone can gain knowledge according to their preferred learning style, when different learning styles are involved in the learning process, students motivation toward learning is increased and knowledge is acquired through the utilization of senses and different perceptions. ${ }^{6}$ According to VARK, knowledge can be acquired through four main sensory modalities, which can be divided into Visual (V), Aural (A), Read/Write $(\mathrm{R})$, and Kinaesthetic (K). A visual type person prefers graphs, charts, and imaging to illustrate the presenting information. An aural type likes learning through lectures, conversations, and recordings. A read/write type prefers printed word as the source of information, using writing as a helpful method for memorizing. A kinaesthetic style likes learning to be through handson experience. Researchers tend to use the VARK questionnaire because it offers simplicity of use, easy access to the algorithm used to calculate the result with excellent reliability and validity. ${ }^{7}$

Various studies have been published to determine the learning preference using VARK in different disciplines like physiology students, health sciences students, dental students, and medical students. ${ }^{8-12}$ Students are not limited to one type of preference. They can be uni-modal, bi-modal or tri-modal, or quad-modal. One study in Riyadh showed that $79.7 \%$ of male and $65.3 \%$ of female medical students were multimodal. ${ }^{12}$ Also, studies assessing learning preference and the influence of gender and academic achievement in medical students have been done. ${ }^{11}$ These show multimodal preference as the most common preference in $68.7 \%$ of the participants. The predominant sensory modality was aural in $45.7 \%$, and no correlation with academic achievement and no significant difference in gender. The influence of gender in choosing the learning preference has been studied in other single-institution studies in our region. ${ }^{12,19}$

This study will assess the preferred sensory modality and the learning preferences by utilizing the VARK questionnaire in medical faculty students at Imam Mohammed Bin Saud Islamic University (IMBSU) and the influence of gender and its relation to academic achievements to help our institute improve the teaching capabilities in the college and also to improve the self-learning strategies for the students.

\section{Methodology}

This study is descriptive and cross-sectional; it was approved by the Research Ethics Committee of IMBSU, with the IRB number 6-2019. We have done the data collection in Riyadh at IMBSU. All medical students of IMBSU were included, the female population in the college of medicine represents $33 \%$ of the total number of the students, then preparatory year students and first-year students were excluded due to the lack of previous GPA. A list of all eligible students' names was compiled and entered into a computer random name generator, which selected the included participants. Every batch leader in male and female batches was asked to distribute the questionnaire using a link to the selected participants. Duplicated and incomplete responses were also excluded. Out of 146 responses, only 113 were complete and included.

The questionnaire has consisted of two sections. The first section concerns gender, educational level, and GPA, which is the measurement of academic performance. The second section contains a VARK questionnaire link that is readily available in Arabic and English languages at the website. At the end, participants were asked to write their score or the result if available. Each participant's score was entered into an Excel sheet and sent to the VARK website to analyze the result and identify each participant's learning preference. VARK survey is known for its high validity and reliability. ${ }^{12}$ Permission to utilize the questionnaire obtained from VARK Learn Limited. Copyright Version 8.01 (2019) held by VARK Learn Limited, Christchurch, New Zealand.

\section{Statistical Analysis}

The sample size was calculated using the formula: $\mathrm{Z}$ is the standard normal variate, given as 1.96 for $5 \%$ type 1 error (P-value $<0.05$ ). With a margin of error of $5 \%$. The estimated sample size was 141. Data were collected and managed in Excel and then entered and analysed by SPSS (version 23). Descriptive statistics using percentages and frequencies were used to describe categorical variables. The level of significance for the P-value was set at $\leq 0.05$. Fischer's exact test was utilized to test for association.

\section{Result}

Figure 1 shows the overall distribution of the preferred model of the participants. The most preferred model was quad-modal (38.1\%), followed by uni-modal preference (30.1\%). As high as $20.4 \%$ of the students had a bimodal preference, and $11.5 \%$ had a tri-modal preference. 


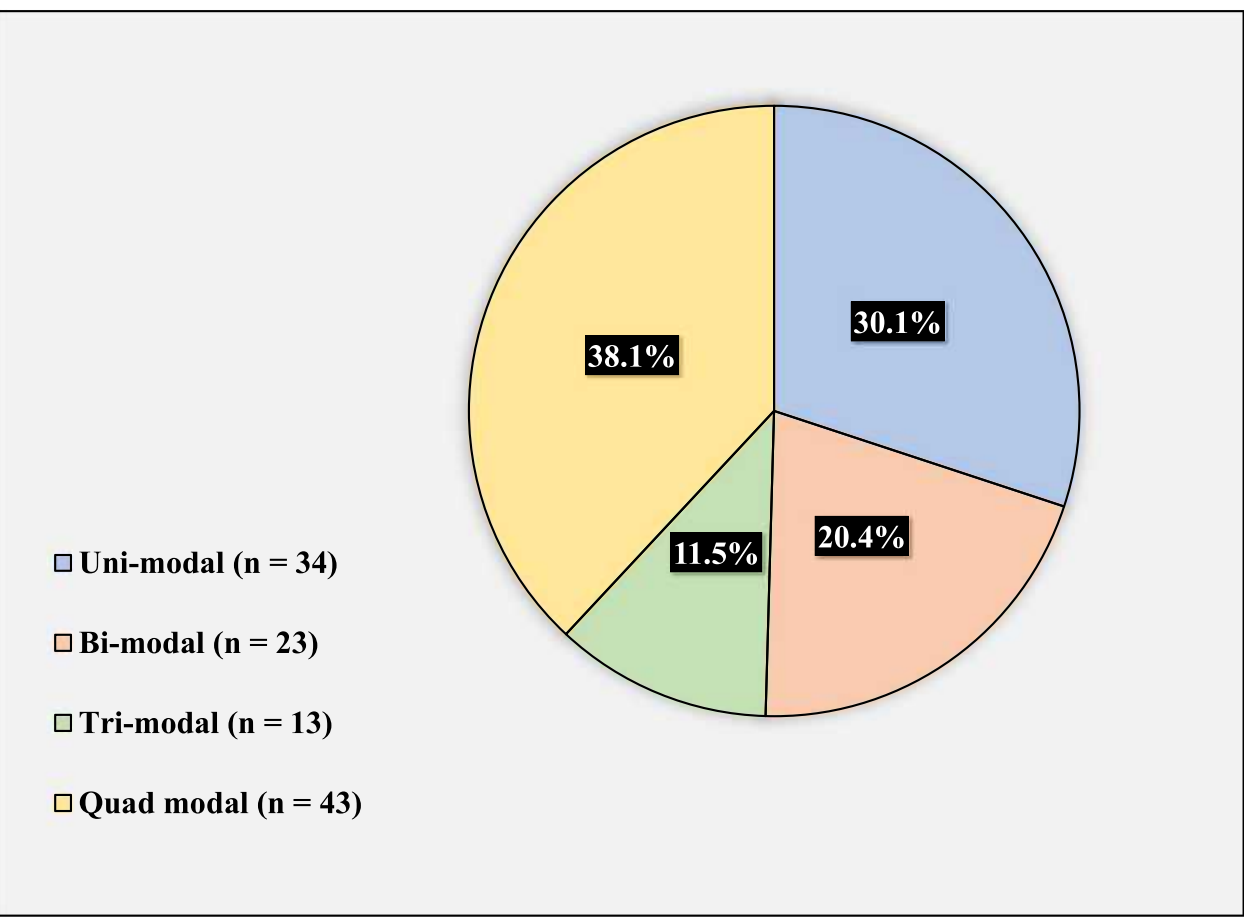

Figure I Overall learning preference distribution.

Figure 2 shows the preferred model among males. Of the 95 male students who participated, $35.8 \%$ had a quad-modal preference, $10.5 \%$ had a tri-modal preference, $20 \%$ had a bimodal preference, and $33.7 \%$ had a uni-modal preference.
Figure 4 shows the specific preferred model among males. Of the 95 male students who participated, 8.4\% had a V-learning preference, $13.7 \%$ had an A-learning preference, $2.1 \%$ had an R-preference, $9.5 \%$ had

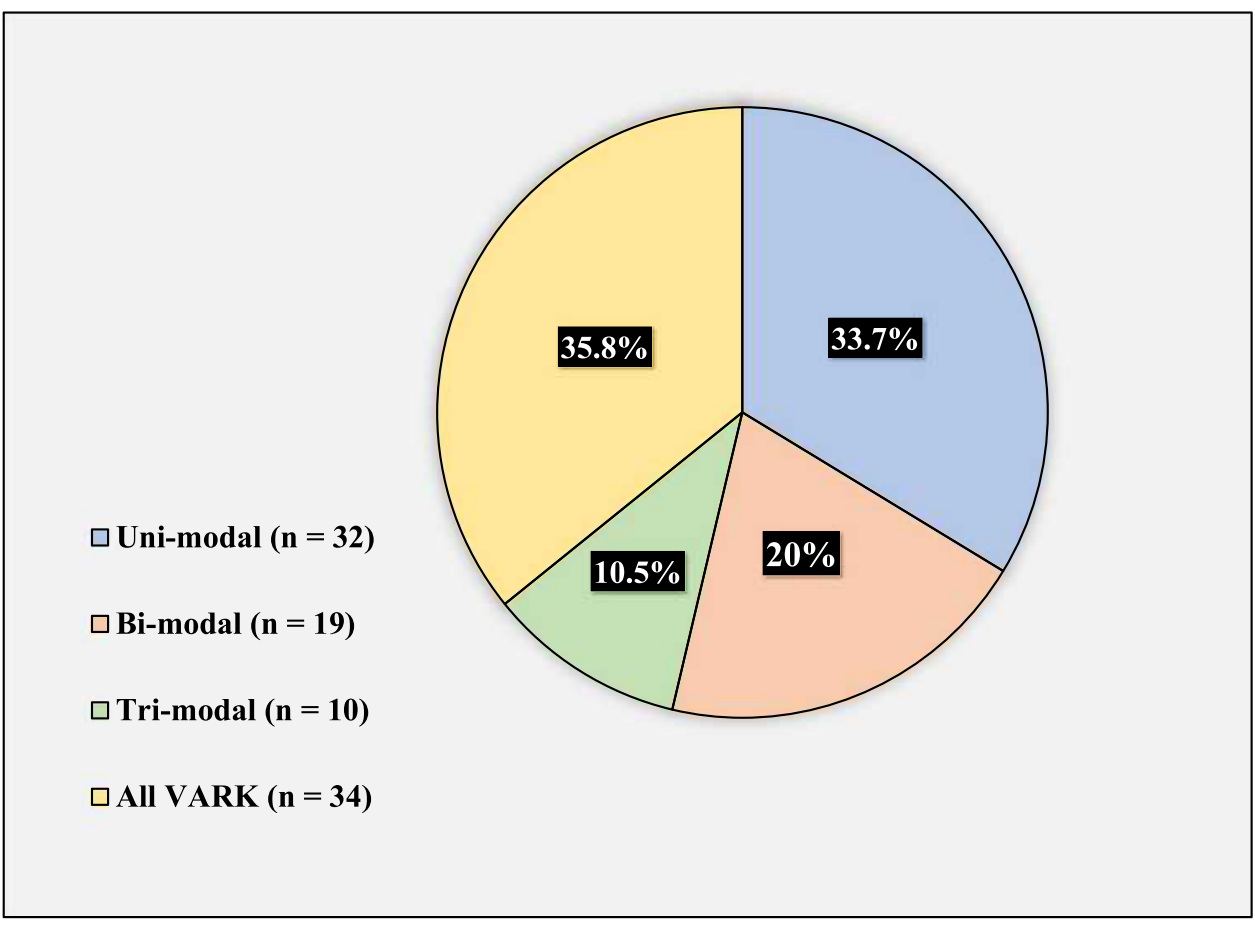

Figure 2 Learning preference distribution in males. 
a K-learning preference, 5.3\% had a VA-learning preference. As high as $1.2 \%$ had a VR-learning preference, $2.1 \%$ had a VK-learning preference, $10.5 \%$ had an AR-learning preference, $2.1 \%$ had an AK-learning preference. As high as $2.1 \%$ had a VAR-learning preference, $4.2 \%$ had a VAKlearning preference, 4.2\% ARK-learning preference. As high as $11.6 \%$ had a VARK Type 1-learning preference,
2.2\% had a VARK Type 2-learning preference, $4.2 \%$ had a VARK transition-learning preference.

Figure 3 shows the preferred model among females. Of the 18 female students who participated, $50 \%(n=9)$ had a quad-modal preference, $16.7 \%$ had a tri-modal preference, $22.2 \%$ had a bi-modal preference, and $11.1 \%$ had a uni-modal preference.

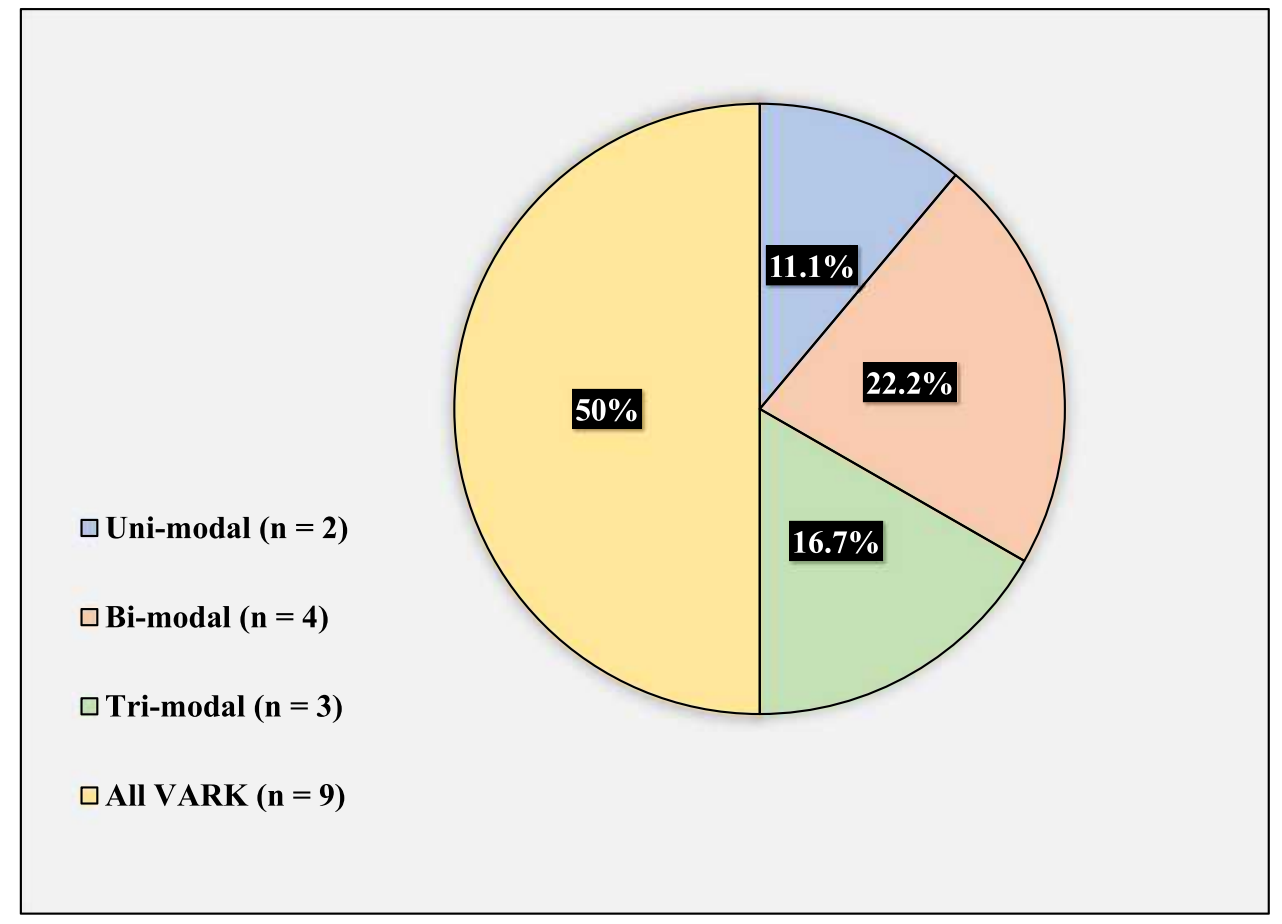

Figure 3 Learning preference distribution in females.

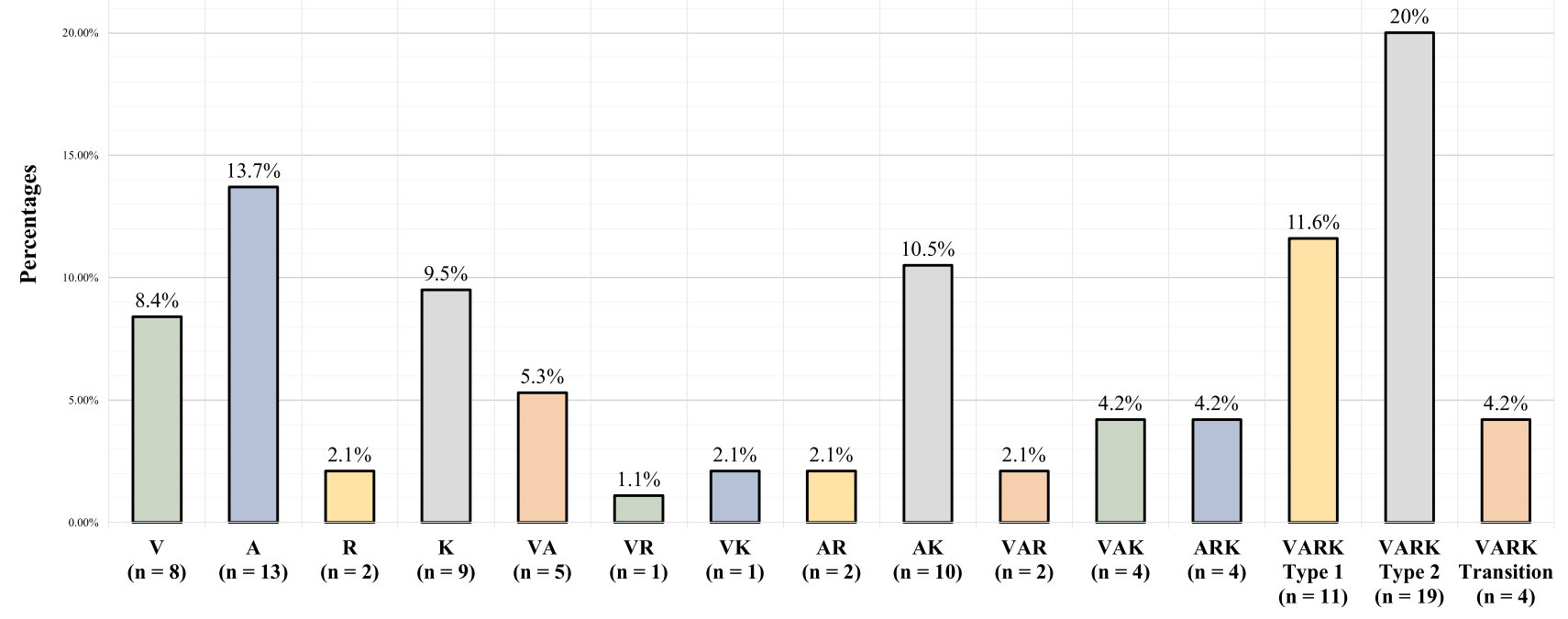

Figure 4 Specific learning preference distribution in male. 


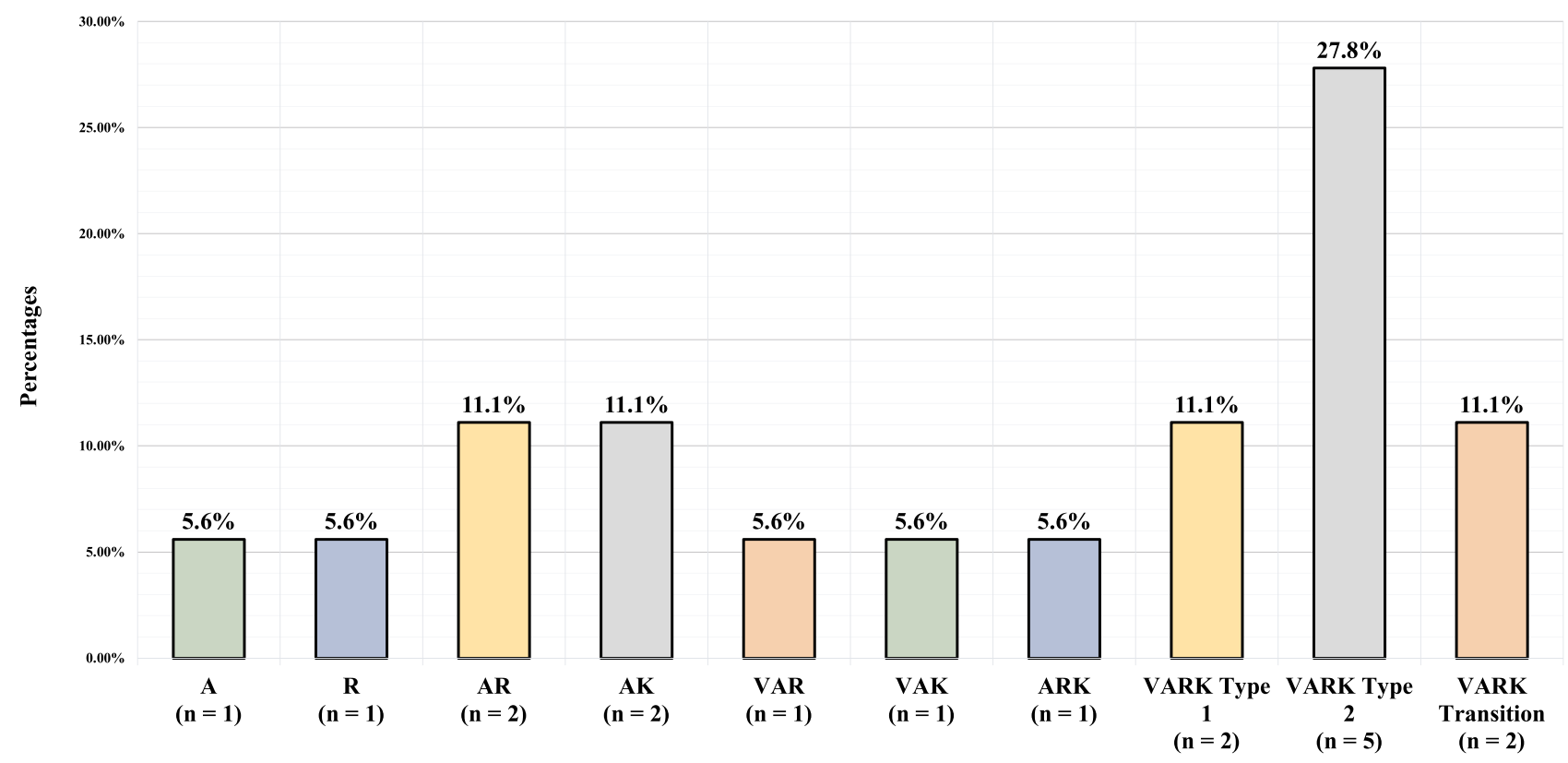

Figure 5 Specific learning preference distribution in females.

Figure 5 shows the specific preferred model among females. Of the 18 female students who participated, $5.6 \%$ had an A-learning preference, $5.6 \%$ had an R-learning preference. As high as $11.1 \%$ had an ARlearning preference, $11.1 \%$ had an AK-learning preference. It also shows that $5.6 \%$ had a VAR-learning preference, $5.6 \%$ had a VAK-learning preference, $5.6 \%$ had an ARK-learning preference. As high as $11.1 \%$ had a VARK Type 1-learning preference, $27.8 \%$ had a VARK Type 2-learning preference, $11.1 \%$ had a VARK transitionlearning preference.

As high as $84.1 \%(\mathrm{n}=95)$ of participants were male, compared to $15.9 \%$ female (Table 1). Most of the participants were in their 3 rd year $(37.2 \%)$, and $30.1 \%$ were in the 4th year (Table 1). The least participated students are 2nd year (15.9\%) and 5th year (16.8\%) students (Table 1). Table 1 also shows the percentage distribution of GPA. As high as $64.6 \%$ of participants were with a GPA above 4 .

Table 2 shows the model preferences based on student GPA. Students with GPA of 4.5-5 who had a quad-modal preference were 17 (51.5\%), who had a tri-modal preference was $3(9.1 \%)$, who had a bi-modal preference was 6 $(18.2 \%)$ and students who had a uni-modal preference were 7 (21.2\%).

Students with GPA 4-4.5 who had a quad-modal preference were 14 (35\%), who had a tri-modal preference were 3 (7.5\%), who had a bi-modal preference were $10(25 \%)$, and students who had a uni-modal preference were 13 (32.5\%).
Students with GPA 3.5-4 who had a quad-modal preference were $5(25 \%)$, who had a tri-modal preference were $4(2 \%)$, who had a bi-modal preference were $4(2 \%)$, and students who had a uni-modal preference were 7 (35\%).

Students with a GPA less than 3.5 who had a quad-modal preference were $7(35 \%)$, who had a tri-modal preference was $3(15 \%)$, who had a bi-modal preference was $3(15 \%)$ and Students who had a uni-modal preference were 7 (35\%).

Table 3 shows Specific Learning Preference Distribution Across GPA. Students with GPA 4.5-5 who preferred VARK type $211(33.3 \%)$. Four (12.1\%) preferred VARK type 1A.

Table I Demographic and Academic Profile of the Participants $(n=113)$

\begin{tabular}{|l|c|c|}
\hline Demographical Characteristics & $\mathbf{n}$ & $\%$ \\
\hline Gender & & \\
Male & 95 & 84.1 \\
Female & 18 & 15.9 \\
\hline Academic Year & & \\
2nd Year & 18 & 15.9 \\
3rd Year & 42 & 37.2 \\
4th Year & 34 & 30.1 \\
5th Year & 19 & 16.8 \\
\hline GPA & & \\
Less than 3.5 & 20 & 17.7 \\
3.5-4 & 20 & 17.7 \\
4-4.5 & 40 & 35.4 \\
$4.5-5$ & 33 & 29.2 \\
\hline
\end{tabular}


Table 2 Learning Preference Distribution Across Academic Year and GPA

\begin{tabular}{|c|c|c|c|c|c|c|c|c|}
\hline & \multicolumn{8}{|c|}{ Academic Year } \\
\hline & \multicolumn{2}{|c|}{ 2nd Year } & \multicolumn{2}{|c|}{ 3rd Year } & \multicolumn{2}{|c|}{ 4th Year } & \multicolumn{2}{|c|}{ 5th Year } \\
\hline & $\mathbf{n}$ & $\%$ & $\mathbf{n}$ & $\%$ & $\mathbf{n}$ & $\%$ & $\mathbf{n}$ & $\%$ \\
\hline \multicolumn{9}{|l|}{ Modal Preference } \\
\hline Uni-Modal & 4 & $22.2 \%$ & 14 & $33.3 \%$ & 8 & $23.5 \%$ & 8 & $42.1 \%$ \\
\hline Bi-Modal & 3 & $16.7 \%$ & 9 & $21.4 \%$ & 9 & $26.5 \%$ & 2 & $10.5 \%$ \\
\hline Tri-Modal & I & $5.6 \%$ & 5 & $11.9 \%$ & 5 & $14.7 \%$ & 2 & $10.5 \%$ \\
\hline \multirow[t]{4}{*}{ Quad Modal } & 10 & $55.6 \%$ & 14 & $33.3 \%$ & 12 & $35.3 \%$ & 7 & $36.8 \%$ \\
\hline & \multicolumn{8}{|c|}{ GPA } \\
\hline & \multicolumn{2}{|c|}{ Less Than 3.5} & \multicolumn{2}{|c|}{$3.5-4$} & \multicolumn{2}{|c|}{$4-4.5$} & \multicolumn{2}{|c|}{$4.5-5$} \\
\hline & $\mathbf{n}$ & $\%$ & $\mathbf{n}$ & $\%$ & $\mathbf{n}$ & $\%$ & $\mathbf{n}$ & $\%$ \\
\hline Modal Preference & & & & & & & & \\
\hline Uni-Modal & 7 & $35 \%$ & 7 & $35 \%$ & 13 & $32.5 \%$ & 7 & $21.2 \%$ \\
\hline Bi-Modal & 3 & $15 \%$ & 4 & $20 \%$ & 10 & $25 \%$ & 6 & $18.2 \%$ \\
\hline Tri-Modal & 3 & $15 \%$ & 4 & $20 \%$ & 3 & $7.5 \%$ & 3 & $9.1 \%$ \\
\hline Quad Modal & 7 & $35 \%$ & 5 & $25 \%$ & 14 & $35 \%$ & 17 & $51.5 \%$ \\
\hline
\end{tabular}

Four (12.1\%) preferred K. 2 (6.1\%) preferred VARK transition. Two $(6.1 \%)$ preferred VAR. Two $(6.1 \%)$ preferred A. Two (6.1\%) preferred R. Two (6.1\%) preferred K. One (3\%) preferred (VAK, AR, VR, and V).

Students with a GPA of 4-4.5 who preferred VARK type 2 were $9(22.5 \%)$. Six (15\%) students preferred AK. Five $(12.5 \%)$ students preferred V. 4 (1\%) students preferred K. Four (1\%) students preferred VARK type 1 . Three $(7.5 \%)$ students preferred A. Two (5\%) students preferred VA. One (2.5\%) students preferred (VARK transition, ARK, VAK, VAR, AR, VK, and R). Students with a GPA of 3.5-4 who preferred A were 5 (25\%). Three (15\%) students preferred VAK.

Two $(10 \%)$ students preferred (VARK type 2, VARK type 1, VA, and K). One (5\%) student preferred VARK transition, ARK, AK, and AR). Students with a GPA of less than 3.5 and preferred A-learning preference are 4 (20\%). Three $(15 \%)$ students preferred VARK type 1 and ARK. Two (10\%) students preferred (VARK transition, VARK type 2, and $\mathrm{V})$. One (5\%) student preferred (AK, AR, VA, and $\mathrm{K})$.

Table 4 shows the P-value explaining gender, academic year, and GPA with the preferred modal and preferred specific style. P-value is appeared to be less than 0.05 in all characteristics.

\section{Discussion}

Having an idea about the diversity of preferred learning preferences among students is crucial for tutors to meet their students' educational needs. This study was performed on medical students of the $2 \mathrm{nd}$, 3rd, 4th, and 5 th year in IMBSU.

One of the significant findings of this study demonstrated that $70 \%$ of the students have a multimodal learning preference, Similarly, Aldosari et al showed that the majority of students had multimodal learning preferences.${ }^{10}$ Other studies also reported that most medical or health sciences students preferred the multimodal learning preference rather than the uni-modal learning approach. ${ }^{12-14}$ Besides, Nuzhat et al studied the relationship between learning preferences and students' gender found that $79.7 \%$ of the males and $65.3 \%$ of the females students preferred the multimodal preference. In comparison, $20.3 \%$ male and $34.7 \%$ female students preferred the unimodal preference. ${ }^{12}$ Moreover, Ramirez reported that $68.9 \%$ of 312 undergraduate students are multimodal learners. $^{15}$

Our study has found that the majority of multimodal students have a quad-modal learning preference, and most of them preferred VARK type 2. That equivalent pattern was apparent when the outcomes were contrasted with John L. Dobson et al study that showed among the 45 multimodal students, the most prominent number was delegated VARK (53\%). Among the bi-modal students, AK was the most liked, which is concurrence with AlSaud et al perception among the Saudi dental understudies and Aldosari et al study. ${ }^{10,16}$ The tri-modal learning 
Table 3 Specific learning Preference Distribution Across Academic Year and GPA

\begin{tabular}{|c|c|c|c|c|c|c|c|c|}
\hline & \multicolumn{8}{|c|}{ Academic Year } \\
\hline & \multicolumn{2}{|c|}{ 2nd Year } & \multicolumn{2}{|c|}{ 3rd Year } & \multicolumn{2}{|c|}{ 4th Year } & \multicolumn{2}{|c|}{ 5th Year } \\
\hline & $\mathbf{n}$ & $\%$ & $\mathbf{n}$ & $\%$ & $\mathbf{n}$ & $\%$ & $\mathbf{n}$ & $\%$ \\
\hline \multicolumn{9}{|l|}{ Learning Preference } \\
\hline V & 1 & $5.6 \%$ & 2 & $4.8 \%$ & 3 & $8.8 \%$ & 2 & $10.5 \%$ \\
\hline A & 2 & $11.1 \%$ & 8 & $19 \%$ & 1 & $2.9 \%$ & 3 & $15.8 \%$ \\
\hline $\mathrm{R}$ & 0 & $0 \%$ & I & $2.4 \%$ & 1 & $2.9 \%$ & I & $5.3 \%$ \\
\hline K & $\mathrm{I}$ & $5.6 \%$ & 3 & $7.1 \%$ & 3 & $8.8 \%$ & 2 & $10.5 \%$ \\
\hline VA & 0 & $0 \%$ & 2 & $4.8 \%$ & 2 & $5.9 \%$ & I & $5.3 \%$ \\
\hline VR & 0 & $0 \%$ & I & $2.4 \%$ & 0 & $0 \%$ & 0 & $0 \%$ \\
\hline VK & 0 & $0 \%$ & 1 & $2.4 \%$ & 0 & $0 \%$ & 0 & $0 \%$ \\
\hline AR & 0 & $0 \%$ & 0 & $0 \%$ & 4 & $11.8 \%$ & 0 & $0 \%$ \\
\hline AK & 3 & $16.7 \%$ & 5 & $11.9 \%$ & 3 & $8.8 \%$ & 1 & $5.3 \%$ \\
\hline VAR & 0 & $0 \%$ & 0 & $0 \%$ & 1 & $2.9 \%$ & 2 & $10.5 \%$ \\
\hline VAK & 1 & $5.6 \%$ & 2 & $4.8 \%$ & 2 & $5.9 \%$ & 0 & $0 \%$ \\
\hline ARK & 0 & $0 \%$ & 3 & $7.1 \%$ & 2 & $5.9 \%$ & 0 & $0 \%$ \\
\hline VARK Type I & 3 & $16.7 \%$ & 5 & $11.9 \%$ & 2 & $5.9 \%$ & 3 & $15.8 \%$ \\
\hline VARK Type 2 & 6 & $33.3 \%$ & 8 & $19 \%$ & 5 & $17.6 \%$ & 4 & $21.1 \%$ \\
\hline \multirow[t]{4}{*}{ VARK Transition } & 1 & $5.6 \%$ & I & $2.4 \%$ & 4 & $11.8 \%$ & 0 & $0 \%$ \\
\hline & \multicolumn{8}{|c|}{ GPA } \\
\hline & \multicolumn{2}{|c|}{ Less Than 3.5} & \multicolumn{2}{|c|}{$3.5-4$} & \multicolumn{2}{|c|}{$4-4.5$} & \multicolumn{2}{|c|}{$4.5-5$} \\
\hline & $\mathbf{n}$ & $\%$ & $\mathbf{n}$ & $\%$ & $\mathbf{n}$ & $\%$ & $\mathbf{n}$ & $\%$ \\
\hline Learning Preference & & & & & & & & \\
\hline V & 2 & $10 \%$ & 0 & $0 \%$ & 5 & $12.5 \%$ & 1 & $3 \%$ \\
\hline$A$ & 4 & $20 \%$ & 5 & $25 \%$ & 3 & $7.5 \%$ & 2 & $6.1 \%$ \\
\hline $\mathrm{R}$ & 0 & $0 \%$ & 0 & $0 \%$ & 1 & $2.5 \%$ & 2 & $6.1 \%$ \\
\hline K & 1 & $5 \%$ & 2 & $10 \%$ & 4 & $10 \%$ & 2 & $6.1 \%$ \\
\hline VA & 1 & $5 \%$ & 2 & $10 \%$ & 2 & $5 \%$ & 0 & $0 \%$ \\
\hline VR & 0 & $0 \%$ & 0 & $0 \%$ & 0 & $0 \%$ & I & $3 \%$ \\
\hline VK & 0 & $0 \%$ & 0 & $0 \%$ & 1 & $2.5 \%$ & 0 & $0 \%$ \\
\hline$A R$ & 1 & $5 \%$ & I & $5 \%$ & 1 & $2.5 \%$ & I & $3 \%$ \\
\hline AK & 1 & $5 \%$ & I & $5 \%$ & 6 & $15 \%$ & 4 & $12.1 \%$ \\
\hline VAR & 0 & $0 \%$ & 0 & $0 \%$ & 1 & $2.5 \%$ & 2 & $6.1 \%$ \\
\hline VAK & 0 & $0 \%$ & 3 & $15 \%$ & 1 & $2.5 \%$ & 1 & $3 \%$ \\
\hline ARK & 3 & $15 \%$ & I & $5 \%$ & 1 & $2.5 \%$ & 0 & $0 \%$ \\
\hline VARK Type I & 3 & $15 \%$ & 2 & $10 \%$ & 4 & $10 \%$ & 4 & $12.1 \%$ \\
\hline VARK Type 2 & 2 & $10 \%$ & 2 & $10 \%$ & 9 & $22.5 \%$ & II & $33.3 \%$ \\
\hline VARK Transition & 2 & $10 \%$ & 1 & $5 \%$ & 1 & $2.5 \%$ & 2 & $6.1 \%$ \\
\hline
\end{tabular}

preference, VAK, and ARK, were both equal in distribution, which was inconsistent with Aldosari et al study, which found that VAK was the preferred preference. Also, Al-Saud's study shows that ARK was the most preferred one.

A key finding in our study is that the second most preferred style for the students $(\mathrm{n}=34)$ is uni-modal learning preference, which agrees with all previous studies. However, one study among Malaysian medical and health sciences students was contradicted by the current study. Overall, the majority of medical and health sciences students $(78.04 \%)$ in the Malaysian study were uni, whereas $17.51 \%$ were bi-modal learners, and $4.45 \%$ were tri-modal learners. None of them was a quadmodal learner. ${ }^{9}$ This difference in preferred learning preference may be attributed to the difference in culture, and those students have a different background in comparison to our participants. 
Table 4 Association Between Demographical and Academic with Participants Learning Preference $(n=113)$

\begin{tabular}{|l|c|}
\hline Characteristics & P-value \\
\hline Association with Preferred Model & \\
Gender & 0.211 \\
Academic Year & 0.772 \\
GPA & 0.660 \\
\hline Association with Preferred Specific Style & \\
Gender & 0.448 \\
Academic Year & 0.756 \\
GPA & 0.370 \\
\hline
\end{tabular}

There was no significant difference in either the preferred model or preferred style in terms of learning preferences among students of different academic years. Nevertheless, we can see students changing the preferred learning preference as they progress throughout the academic years due to introducing lectures primarily in a directive manner towards more practical patterns. ${ }^{17}$

In this study, the predominant learning preference in all years is multimodal $(n=79)$. This is in concurrence with the study done on undergraduate dental students at Babol University of Medical Sciences, which revealed that most undergraduate students liked to utilize numerous learning preferences. ${ }^{18}$

The quad-modal is preferred in second-year students, whereas the fifth-year student $(42.10 \%)$ preferred unimodal preference. Among third-year students, uni-modal and quad-modal preference is equally the same (33.3\%). Almost a third of the fourth-year students (12 out of 34) prefer quad-modal preference.

There are limited studies that demonstrate learning preference concerning the academic year of study. However, Aldosari et al found that second-year students were more likely to prefer uni-modal learning than firstyear students. Still, no other discrepancies between academic years were found. ${ }^{11}$ It also stated that uni-modal learning preference grows as students shift from third to fourth in dental school. ${ }^{10}$ Furthermore, investigations are needed in this area, as there are no sufficient studies to support the present study.

Regarding learning preference in males and females, both genders have similar findings regarding the most common learning preference, which is VARK $2(20 \%)$ in males and $(27.80 \%)$ in females. This is consistent with Urval et al study, in which they reveal no differences in both genders. Another support of this claim is Nasser
AlQahtani et al study, where they observed that the most common learning preference in both genders is VARK. ${ }^{19}$ On the other hand, Nuzhat et al study showed that females' most common learning preference was VRK, while in males, it was VARK. ${ }^{12}$ The second most common learning preference in the male population is $\mathrm{A}(13.70 \%)$. In contrast, the female population showed similar results $(11.60 \%)$ for the four different learning preferences, VARK type 1, VARK transition, AR, and AK. This supports the observation of Balasubramaniam et al study, where they found that the A category is more prevalent in the male population. ${ }^{20}$ These findings disagree with Nasser AlQahtani et al study that claims that females are better listeners than males. Thus, they can benefit more from traditional teachings, such as lectures. ${ }^{19}$

Our study shows the male population has more combination of learning preferences than female; This disagrees with two previous studies that concluded that the female population has more diversity of learning preferences; for example, in Balasubramaniam et al study, female students have more combination of learning preferences in both bimodal and tri-modal learning preferences. ${ }^{12,20}$

Regarding uni-modal and multimodal preferences, it seems that both genders prefer multimodal preference. Our study found that females prefer multimodal preference more than males ( $50 \%$ females, $35.38 \%$ males). This supports Breckler et al study, which found that female preference of multimodal was $62 \%$ while males $54 \% .{ }^{21}$ Yet, all these findings are not significant. However, this contradicts Balasubramaniam et al study, which revealed that the male population prefers multimodal more than females. ${ }^{20}$

When it comes to uni-modal learning preference, males showed slightly higher scores preferring uni-modal learning preference (33.7\% males, $11.1 \%$ females), which is inconsistent with the Wehrwein et al study where most of the students preferring uni-modal learning preference are females. ${ }^{22}$ In the male population, the dominant uni-modal was $A(13.7 \%)$, while females $A$ and $R$ have the same prevalence $(5.60 \%)$. These similarities between male and female populations disagree with Dobson et al study, which found that males differ from females regarding the most common preferred uni-modal learning preference. ${ }^{22}$

Our study showed no huge variation observed in the favored learning model or preferred learning styles between males and females. These conclusions support Balasubramaniam et al study in which they deny any similarity among males and females regarding learning preferences. ${ }^{20}$ On the other hand, two previous studies 
had opposite findings. ${ }^{12,23}$ Nuzhat et al found significant variation between males and females regarding the preferred learning model. ${ }^{12}$ Furthermore, Wehrwein et al study claimed that there is a difference between the genders regarding learning preference. ${ }^{23}$

To measure academic performance, participants were asked about their grade point average (GPA). The majority of participants $(n=80)$ have a GPA of 4.5 or less. Among those, most of them were multimodal $(n=53)$. Quad-modal was the most preferred modality in these groups in total. As high as $80.6 \%$ of the people with the highest GPA have a multimodal preference, with almost half of them were quad-modal. There was no significant difference observed in the preferred learning model or the preferred learning style concerning GPA, such as academic performance. These findings are the same as other studies that used VARK to assess learning preference. ${ }^{24,25}$ Some researchers used different tools to evaluate learning preferences and their relation to academic performance, and they also indicated no association. ${ }^{26,27}$ However, one study has linked higher final exam scores for students who lack visual preference. Another one has shown participants with aural learning style preferences are associated with higher grades in the United States Medical License Examination (USMLE). Still, this association is not significant in a later multi-institutional study. ${ }^{26,28,29}$ Furthermore, another study was done among dental students says that participants with visual preference had higher average exam scores. ${ }^{18}$

\section{Limitations}

There were several limitations pertaining to this study. The findings could not be generalized owing to the restricted number of participants from a single institute. First-year medical students were not included in the study either since they had no GPA scores, which was the primary tool employed by the study to assess the students' academic performance. Responses from female students were deemed inadequate for this study since the college had fewer female students than its male student population.

\section{Conclusion}

In this study, several important variations between learning style preferences across academic levels and genders were observed and their impact on the students' academic performance. A majority of the participants were observed to have a preference for a multimodal learning method. No statistically significant differences were observed between male and female students concerning their learning preferences. The participants' preferred learning style or learning model was also observed to have no statistically significant impact on their GPA and academic performance. The authors recommend further research studies to be conducted on this subject involving a larger student population from multiple institutions.

\section{Disclosure}

The authors declare that there are no conflicts of interest.

\section{References}

1. Reid J. Learning Styles in the ESL. 1st ed. New York: Heinle \& Heinle; 1995.

2. Lujan HL. First-year medical students prefer multiple learning styles. AJP Adv Physiol Educ. 2006;30(1):13-16. doi:10.1152/advan.000 45.2005

3. Thepsatitporn S, Pichitpornchai C. Visual event-related potential studies supporting the validity of VARK learning styles' visual and read/write learners. Adv Physiol Educ. 2016;40(2):206-212. doi:10.1152/advan.00081.2015

4. Kolb DA. Management and the Learning Process. Calif Manage Rev. 1976;18(3):21-31. doi:10.2307/41164649

5. VARK - A Guide to Learning Styles. VARK - A Guide To Learning Styles; 2021. Available from: https://vark-learn.com. Accessed January, 52021.

6. Mills DW. Applying what we know student learning styles; 2002. Available from: http://robert-vroman.com/resources/Applying\% 20What\%20We\%20Know.pdf. Accessed January 5, 2021.

7. Leite WL, Svinicki M, Shi Y. Attempted validation of the scores of the VARK: learning styles inventory with multitrait-multimethod confirmatory factor analysis models. Educ Psychol Meas. 2010;70 (2):323-339. doi:10.1177/0013164409344507

8. Dobson JL. Learning style preferences and course performance in an undergraduate physiology class. Adv Physiol Educ. 2009;33 (4):308-314. doi:10.1152/advan.00048.2009

9. Wong RSY, Siow HL, Kumarasamy V, Shaherah Fadhlullah Suhaimi N. Interdisciplinary and inter-institutional differences in learning preferences among Malaysian medical and health sciences students. J Adv Med Educ Prof. 2017;5(4):164-171.

10. Aldosari MA, Aljabaa AH, Al-Sehaibany FS, Albarakati S. Learning style preferences of dental students at a single institution in Riyadh, Saudi Arabia, evaluated using the VARK questionnaire. Adv Med Educ Pract. 2018;9:179-186. doi:10.2147/AMEP.S157686

11. Urval RP, Kamath A, Ullal S, Shenoy AK, Shenoy N, Udupa LA. Assessment of learning styles of undergraduate medical students using the VARK questionnaire and the influence of sex and academic performance. AJP Adv Physiol Educ. 2014;38(3):216-220. doi:10. 1152/advan.00024.2014

12. Nuzhat A, Salem RO, Al HN, Ashour N. Gender differences in learning styles and academic performance of medical students in Saudi Arabia. Med Teach. 2013;35((SUPPL. 1). doi:10.3109/0142 159X.2013.765545

13. Sarabi-Asiabar A, Jafari M, Sadeghifar J, et al. The relationship between learning style preferences and gender, educational major and status in first-year medical students: a survey study Iran. Iran Red Crescent Med J. 2014;17(1):e18250. doi:10.5812/ircmj.18250

14. Thomas C, Kodumuri PK, Saranya P. How do medical students learn? A study from two medical colleges in south India - A cross-sectional study. Int J Med Res Heal Sci. 2015;4(3):502. doi:10.5958/2319-5886.2015.00097.1 
15. Ramirez BU. The sensory modality used for learning affects grades. AJP Adv Physiol Educ. 2011;35(3):270-274. doi:10.1152/advan. 00010.2011

16. Al-Saud LM. Learning style preferences of first-year dental students at King Saud University in Riyadh, Saudi Arabia: influence of gender and GPA. $J$ Dent Educ. 2013;77(10):1371-1378. doi:10.1002/j.00220337.2013.77.10.tb05612.x

17. Murphy RJ, Gray SA, Straja SR, Bogert MC. Student learning preferences and teaching implications. $J$ Dent Educ. 2004;68 (8):859-866. doi:10.1002/j.0022-0337.2004.68.8.tb03835.x

18. Nasiri Z, Gharekhani S, Ghasempour M. Relationship between learning style and academic status of Babol dental students. Electron Physician. 2016;8(5):2340-2345. doi:10.19082/2345

19. AlQahtani N, AlMoammar K, Taher S, AlBarakati S, AlKofide E. Learning preferences among dental students using the VARK questionnaire: a comparison between different academic levels and gender. J Pak Med Assoc. 2018;68(1):59-64.

20. Balasubramaniam G, Indhu KA. Study of learning style preferences among first-year undergraduate medical students using VARK model. Educ Med J. 2016;8(4):15-21. doi:10.5959/eimj.v8i4.440

21. Breckler J, Joun D, Ngo H. Learning styles of physiology students interested in the health professions. Adv Physiol Educ. 2009;33 (1):30-36. doi:10.1152/advan.90118.2008

22. Dobson JL. A comparison between learning style preferences and sex, status, Irand course performance. Adv Physiol Educ. 2010;34 (180):197-204. doi:10.1152/advan.00078.2010.-Students
23. Wehrwein EA, Lujan HL, DiCarlo SE. Gender differences in learning style preferences among undergraduate physiology students. Adv Physiol Educ. 2007;31(2):153-157. doi:10.1152/advan.00060.2006

24. Almigbal TH. Relationship between the learning style preferences of medical students and academic achievement. Saudi Med J. 2015;36 (3):349-355. doi:10.15537/smj.2015.3.10320

25. Mozaffari HR, Janatolmakan M, Sharifi R, Ghandinejad F, Andayeshgar B, Khatony A. The relationship between the VARK learning styles and academic achievement in dental students. $A d v$ Med Educ Pract. 2020;11:15-19. doi:10.2147/AMEP.S235002

26. Suliman WA. The relationship between learning styles, emotional social intelligence, and academic success of undergraduate nursing students. J Nurs Res. 2010;18(2):136-143. doi:10.1097/JNR.0b013e 3181dda797

27. Bhalli MA, Khan IA, Sattar A. Learning style of medical students and its correlation with preferred teaching methodologies and academic achievement. J Ayub Med Coll Abbottabad. 27(4):837-842.

28. Kim RH, Gilbert T. Learning style preferences of surgical residency applicants. J Surg Res. 2015;198(1):61-65. doi:10.1016/j.jss.2015. 05.021

29. Kim RH, Kurtzman SH, Collier AN, Shabahang MM. The learning preferences of applicants who interview for general surgery residency: a multi-institutional study. J Surg Educ. 2016;73(6):e136e141. doi:10.1016/j.jsurg.2016.06.013
Advances in Medical Education and Practice

\section{Publish your work in this journal}

Advances in Medical Education and Practice is an international, peerreviewed, open access journal that aims to present and publish research on Medical Education covering medical, dental, nursing and allied health care professional education. The journal covers undergraduate education, postgraduate training and continuing medical education including emerging trends and innovative models linking education, research, and health care services. The manuscript management system is completely online and includes a very quick and fair peer-review system. Visit http://www.dovepress.com/testimonials.php to read real quotes from published authors. 